\title{
ELECTROENCEPHALOGRAPHIC WARNING OF IMPENDING LOCALIZED CEREBRAL DISORDER DURING ANAESTHESIA
}

\author{
Max S Sadove, M.D., Cecil G. Yarbrough, M.D, \\ Meredith Murray, M D., and Dorothy R. BeCKA ${ }^{1}$
}

DURING THE LAST TWO YEARS contmuous electroencephalograms have been taken during surgical cases in an effort to correlate the changes in the brain wave patterns with the depth of anaesthesia We have had the opportunity to study a variety of anaesthetic agents, and to observe the more or less gradual development of various critical conditions in a number of our cases One of these we have reported (1), but the present case is basically different and of sufficient general interest to warrant a detailed description As will be explamed in the body of this report, we were able to watch the development of a localized epileptic discharge in a patient with a pre-existung neurological lesion. Apparently the anaesthetic technique and/or the operative procedure aggravated the focal disorder and precipitated the cerebral symptoms

A retropubic prostatectomy was performed on a poor ins patient with a history of an old cerebrovascular accident The electroencephalogram was used for purposes of study and as a control to keep the patient at an analgesic level It has been our experience that the electroencephalogram is an excellent tool which aids the anaesthesiologist in maintaning a patient at the desired level of analgesia or surgical anaesthesia It was during this surgical procedure that the electroencephalogram recorded a right cortical seizure fully two minutes before a left-sided Jacksonian seizure was noted clinically

\section{Patient's History}

A 67-year-old white male was admitted April 12, 1958 with a diagnosis of acute urinary retention Physical examination revealed blood pressure of $130 / 75$ and a regular julse There was a left lower facial paresis, and some deviation of the head to the -eft Pupls were equal and reacted to light and accommodation Extra-ocular movements were normal Control of fine movements was absent in the left hand and there was residual weakness of the left side of his body The remainder of the neurological exammation gave normal findin $x$ s for the patient's age Prostate was found to be 2 to 3 plus enlarged and nodular the electrocardiograp.uc tracing revealed coronary insufficiency and ventricular strain Serology was negative with blood count and urinalysis reported within normal limits The satient had a history of hysertension and cerebrovascular accident in 1947 at whic 1 time there was a hypoaest.nesia of the left side of the face Comeal reflexes were apparent on the left When the patient's jaw was opened, there was a deviation to the rnght There was left facial droop and the tongue deviated left with some tremor The shoulder muscles were weak on the left. Hypoaesthesia existed on the left and the deep tendon reflexes were absent that side

${ }^{1}$ Division of Anaesthesiology, University of Illmois, Research and Educational Hospitals, Chicago 12, Ill.

Can Anaes Soc J, vol 6, no 3, July, 1959 


\section{Procedure and Findings}

A Grass 8 Channel Model III Electroencephalograph was used outside the operatıng room door. Six solder disc electrodes were applied with electrode paste to the frontal and precentral areas bilaterally, both ears being used as a reference. A lead 2 electrocardiogram was recorded simultaneously with the electroencephalogram.

The premedication utılized was Nembutal $100 \mathrm{mg}$., morphine sulphate $10 \mathrm{mg}$. and atropine sulphate $.4 \mathrm{mg}$. at $6 \mathrm{~A} \mathrm{M}$. the day of surgery. Blood pressure prior to surgery was $116 / 88$.

A short, control electroencephalogram was taken following preoperative sedaton, but before anaesthesia was started. This record showed an irregular but symmetrical low voltage tracing ( $F_{1} g$ 1) which was considered to be within normal limits. It was felt that a longer wake record or a sleep record might have revealed an abnormality. The patient was given thiopental sodiun 475
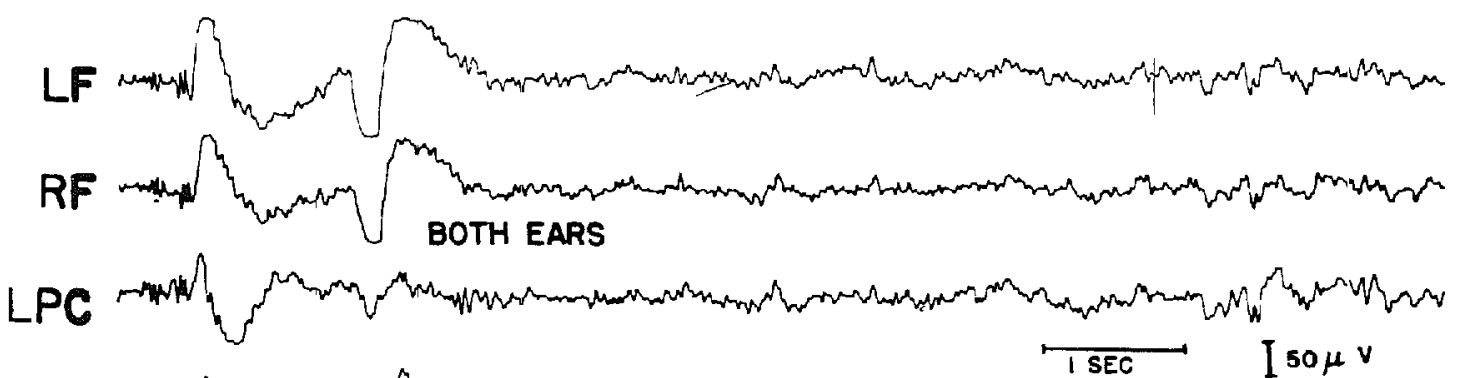

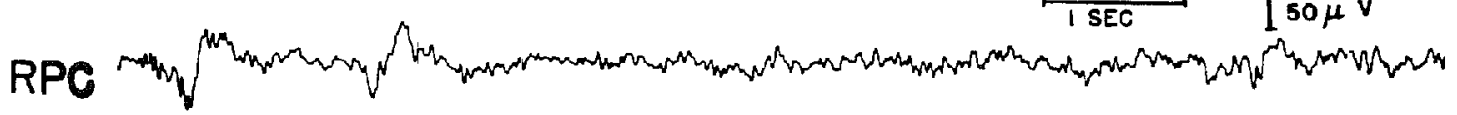

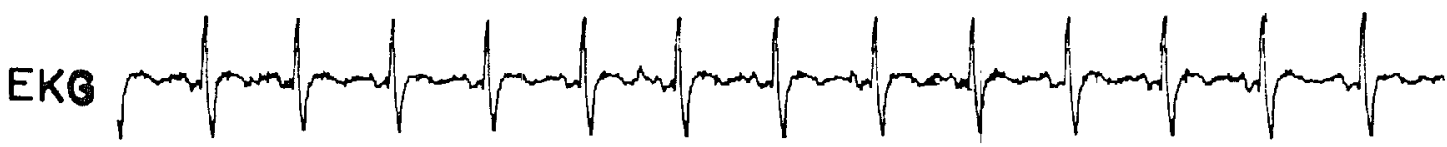

Figure 1 Irregular but symmetrical low voltage tracing considered within normal limits Bifrontal eye artifacts

$\mathrm{mg}$, followed by succinylcholine $40 \mathrm{mg}$ at $8: 17 \mathrm{~A} \mathrm{M}$, mtubation was performed at 820 , and ether and oxygen, closed circuit technique, was started at 8:22 A.M. The operative procedure was started at 8.30 and the blood pressure at that time was 138/90. The EEG pattern showed a high voltage, fast, 13 to 15 per second activity with a mild amplitude asymmetry, the right frontal and on rare occasions the right precentral leads were lower in amplitude than the left (Fig 2). This fast activity, as recorded in the electroencephalogram, is considered as the "analgesic level" of anaesthesia (2). At 8.45, a fast spike seızure discharge was noted in the right frontal area ( $F_{1 g} 3$ ). This constant seizure activity was noted in the electroencephalogram for approximately 2 minutes before the surgeon sald, "The patient's left arm is vibrating," and this continued for another minute. Because of draping no other movements were noted. Attempts to deepen the plane of anaesthesia with a small amount of ether lowered the blood pressure. Figure 4 shows large slow waves in the left frontal and both precentral areas. 


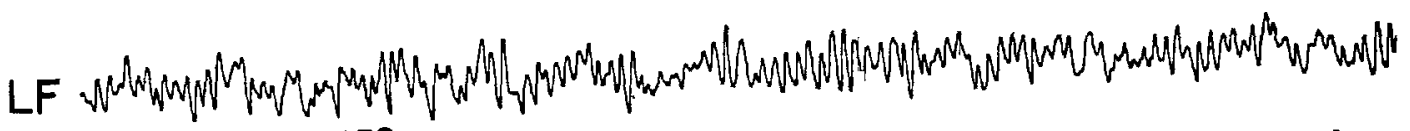

\section{BOTH EARS}

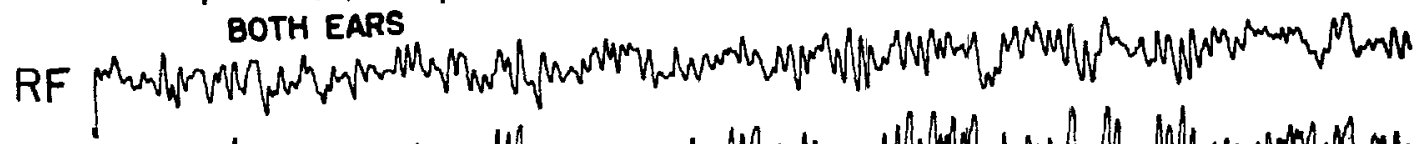

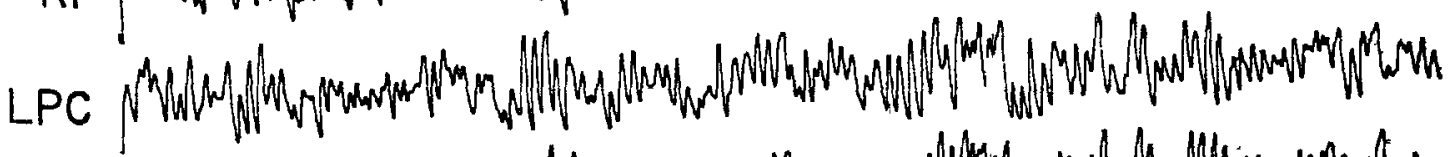

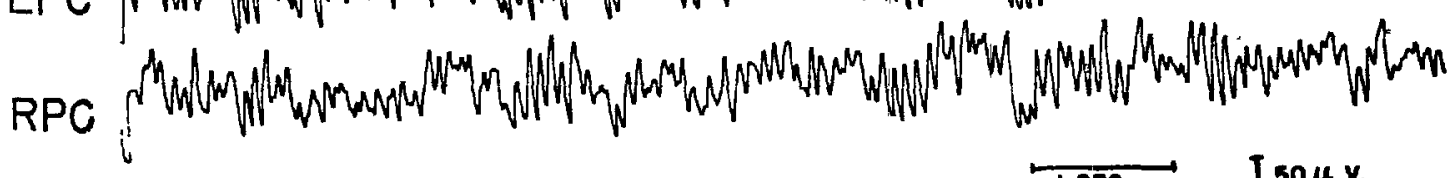

EKG

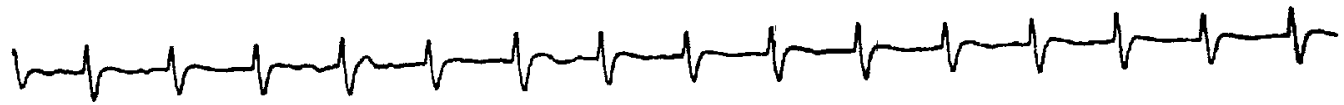

FIGURE 2 High voltage fast 13 to 15 per second activity with a muld amplitude asymmetry, the right frontal showing lower amplitude than the left This fast activity is considered "analgesic level" of anesthesia

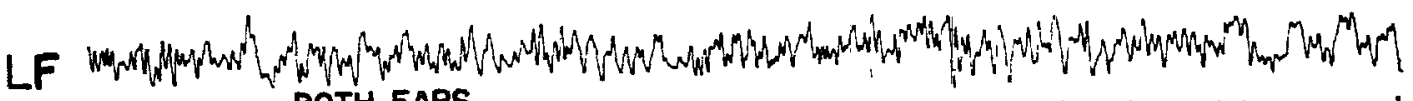
BOTH EARS

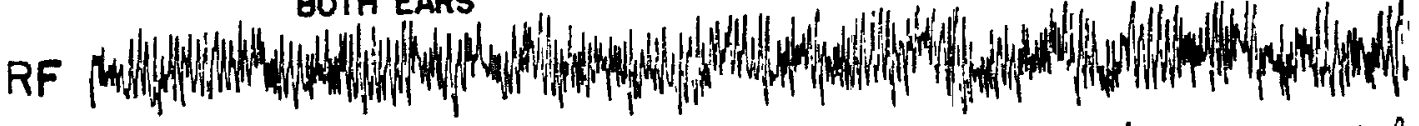

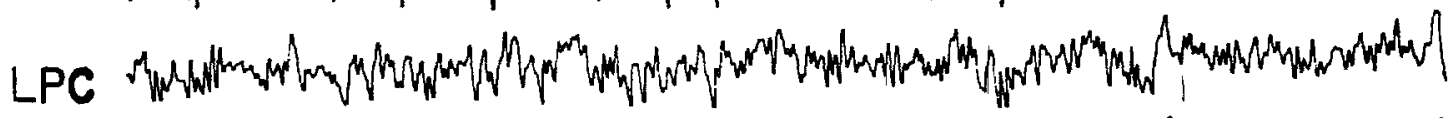

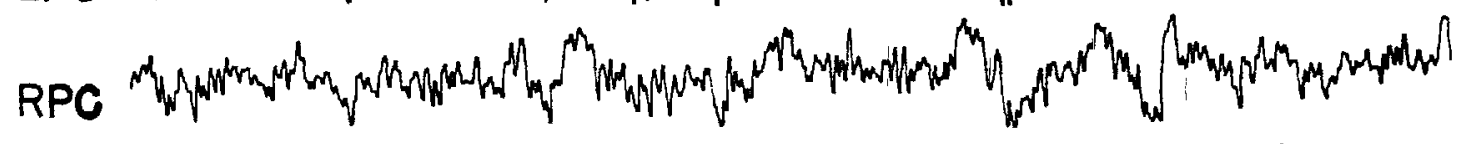

EKG

$$
\text { TSEC. I } 50 \mu \mathrm{v} \text {. }
$$

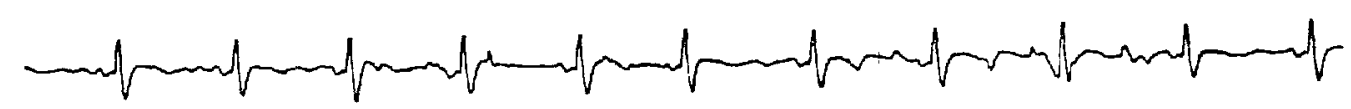

FIGURE 3 Constant fast spike seizure activity in the nght frontal area

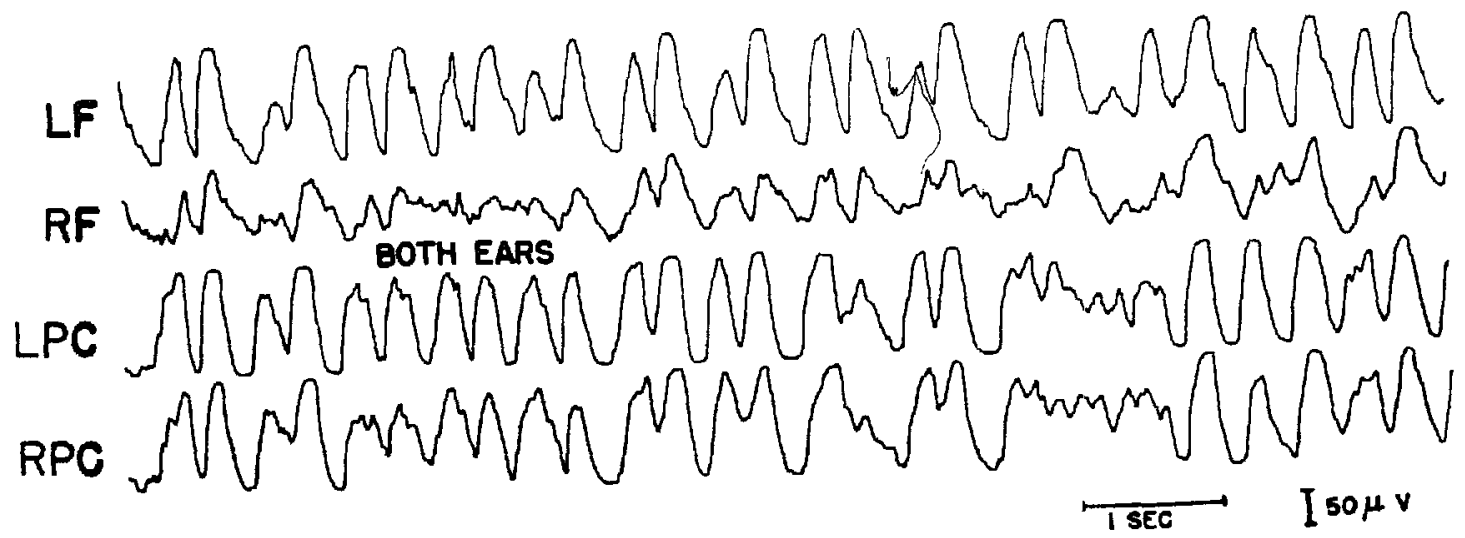

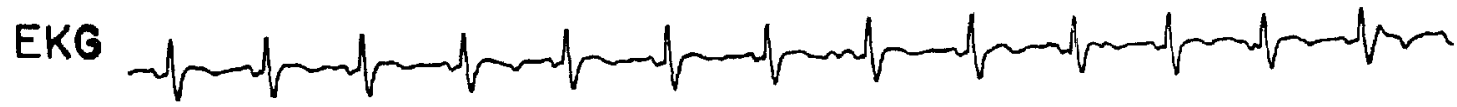

Figure 4. Large slow 2 to 3 per second waves in the left fruntal and both precentral leads Right frontal shows a marked depression in the amplitude and difference in frequency, possibly due to a localized post serzure exhaustion. 
These patterns and this frequency ( 2 to 3 per second) are characteristic of the surgical level of anaesthesia (2). However, a marked depression in the amplitude and a difference in frequency were apparent in the right frontal area, possibly due to a localized post-seizure exhaustion. The patient was permitted to return to the previous analgesic level of anaesthesia (fast activity), and the electroencephalogram showed the same mild asymmetry noted in Figure 2 . The subsequent surgical and anaesthetic course was otherwise uneventful and terminated at 10.25 .

Postoperatively the patient developed hypostatic pneumonia. An .electroencephalogram was taken one month following the surgery and showed a mild and inconstant focal slowing in the right anterior temporal-right temporal areas with occasional left temporal-left anterıor temporal involvement (Fig. 5).

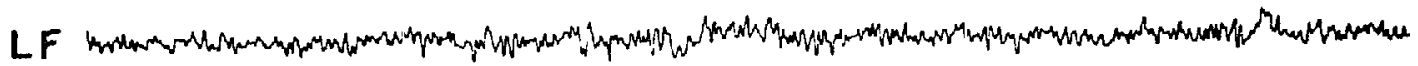

RF

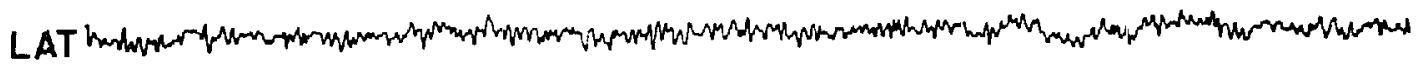
LEFT OCCIPITAL

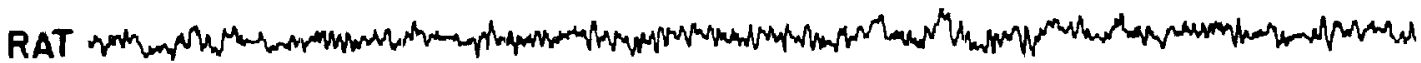

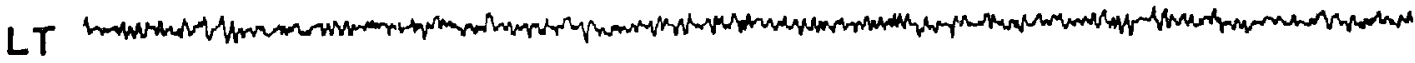

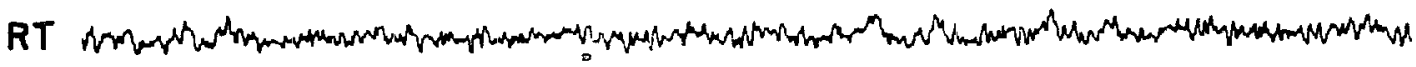

LEar

Figure 5 Mild focal slowing an the right antenor temporal-right temporal areas Electroencephalogram taken one month after surgery

A neurological examination done on June 25,1958 , approximately one month after surgery, revealed an alert and co-operative patient with a marked dysarthria, moderate left hemiparesss, greater in the upper than in the lower extremity; all deep tendon reflexes were increased in the left upper extremity and decreased in the left lower extremity. as compared to the right There was a marked left supranuclear facial paresis Pulsations in the right internal carotid artery are definitely decreased as compared to the left Compression of the left internal carotid artery produced a short episode of unconsciousness

In the literature, many factors were advanced as causes and conflicting evidence was noted, with authorities incriminating the following precipitants for convulsions associated with general anaesthesia: epileptic liability $(3-4)$, toxaemia, septicaemia, excess or deficiency of $\mathrm{CO}_{2}$, impurities in ether and in 
oxygen, deep or light anaesthesia, faulty methods of anaesthesia, hypoglycaemia, atropıne, alkalosis, overbreathing, disturbance in calcuum metabolism, ketosis, cerebral anaemia, cerebral injury or accident, increased cerebral blood flow, hydration of protein particles in the plasma, convulsant poisons, hyperthermia (5), hyperpyrexia and respiratory acidosis (6), or that the underlying cause was a temporary, easily reversible derangement of physiology, rather than a convulsive diathesis (7).

\section{Comment}

We have found the electroencephalogram to be an excellent tool with which to check the constancy and depth of anaesthesia. The electroencephalogram can also give important information which will illuminate the nature and give clues as to the cause of sudden or gradual deterioration of the patient's condition. This is particularly true in cases where convulsive phenomena develop during surgery or during anaesthesia. In the present case the presumption might have arisen that the patient was suffermg from a generalized anoxia. The electroencephalogram shows that this was not true The premonitory flare-up of fast spike activity in the right frontal area gave ample warning of a localized disturbance and gave the anaesthesiologist an opportunity to take protective measures. The deepening of the anaesthesia obviously stopped the seizure discharge. The question remains as to whether or not it benefited the disturbed neurons. It may have added further insult to the pre-existing injury. These are questions which we cannot answer, but they would not even have arisen and could not have been asked if an electroencephalographic recordung had not been made at the time It is obvious from this case that a single lead placement or a mid-line bipolar placement would have prover, of relatively hittle value. In our opmion, at least one and preferably two leads should be placed over each hemisphere

\section{REFERENCES}

I Tentler, R L, Sadove, Max, Becka, Donothy R, \& Taylor, Robert C Electroencephalographic Evidence of Cortical "Death" Frllowed by Full Recovery (Protective Action of Hypothermia) J A M A 164 1668-1670 (Aug 10, 1957).

2 Artusto, Joseph F, Jr Ether Analgesia during Major Surgery, J A M A. 157 33-36 ( Jan 1, 1955)

3 Lundy, Joms S Convulsions Associated with General Anesthesia Surgery 1 666-683 (1937)

4 Wicliams, Denis \& Sweet, William II The Constitutional Factor in Anesthetic Convulsions Lancet 2 430 -433 (Sep 30, 1944)

5 Owens, Guy, Dawson, Royce E, \& Scotr, H Wirliam, Jr Clinical and Expenmental Expenences with Ether Convulsions Surg, Gynec \& Obst 105 681-686 (Dec, 1957)

6 Cassels, W. H, Becker, T J, \& Seevers, M H Convulsions durng Anesthesia Anesthesiology 1 56-67 (1940)

7 Kreuter, George C Convulsions dunng Anesthesia Wisconsin M J 54 229-230 (1955) 